\title{
Pharmacotherapy of elderly patients in everyday anthroposophic medical practice: a prospective, multicenter observational study
}

Elke Jeschke ${ }^{1 *}$, Thomas Ostermann², Manuela Tabali ${ }^{1}$, Horst C Vollmar ${ }^{3,4}$, Matthias Kröz ${ }^{1}$, Angelina Bockelbrink ${ }^{5}$, Claudia M Witt ${ }^{5}$, Stefan N Willich ${ }^{5}$, Harald Matthes $^{1}$

\begin{abstract}
Background: Pharmacotherapy in the older adult is a complex field involving several different medical professionals. The evidence base for pharmacotherapy in elderly patients in primary care relies on only a few clinical trials, thus documentation must be improved, particularly in the field of complementary and alternative medicine (CAM) like phytotherapy, homoeopathy, and anthroposophic medicine. This study describes diagnoses and therapies observed in elderly patients treated with anthroposophic medicine in usual care.
\end{abstract}

Methods: Twenty-nine primary care physicians in Germany participated in this prospective, multicenter observational study on prescribing patterns. Prescriptions and diagnoses were reported for each consecutive patient. Data were included if patients were at least 60 years of age. Multiple logistic regression analysis was used to determine factors associated with anthroposophic prescriptions.

Results: In 2005, a total of 12314 prescriptions for 3076 patients (68.1\% female) were included. The most frequent diagnoses were hypertension (11.1\%), breast cancer (3.5\%), and heart failure (3.0\%). In total, 30.5\% of the prescriptions were classified as CAM remedies alone, $54.4 \%$ as conventional pharmaceuticals alone, and $15.1 \%$ as a combination of both. CAM remedies accounted for $41.7 \%$ of all medications prescribed (35.5\% anthroposophic). The adjusted odds ratio (AOR) for receiving an anthroposophic remedy was significantly higher for the first consultation ( $\mathrm{AOR}=1.65$; $\mathrm{Cl}$ : 1.521.79), treatment by an internist ( $A O R=1.49 ; \mathrm{Cl}: 1.40-1.58)$, female patients ( $A O R=1.35 ; \mathrm{Cl}: 1.27-1.43)$, cancer $(\mathrm{AOR}=4.54$; Cl: 4.12-4.99), arthropathies ( $A O R=1.36 ; \mathrm{Cl}: 1.19-1.55)$, or dorsopathies ( $\mathrm{AOR}=1.34 ; \mathrm{Cl}: 1.16-1.55)$ and it decreased with patient age $(A O R=0.97 ; \mathrm{Cl}: 0.97-0.98)$. The likelihood of being prescribed an anthroposophic remedy was especially low for patients with hypertensive diseases ( $A O R=0.36$; Cl: 0.32-0.39), diabetes mellitus ( $A O R=0.17$; Cl: 0.14-0.22), or metabolic disorders (AOR $=0.17 ; \mathrm{Cl}: 0.13-0.22$ ).

Conclusion: The present study is the first to provide a systematic overview of everyday anthroposophic medical practice in primary care for elderly patients. Practitioners of anthroposophic medicine prescribe both conventional and complementary treatments. Our study may facilitate further CAM-research on indications of, for example, dementia or adverse drug reactions in the elderly.

\section{Background}

With average life expectancy increasing and birth rates declining, the proportion of elderly people expands in almost every developed country. Due to this demographic shift, in Germany the proportion of elderly people is expected to rise from 20 to $34 \%$ within the next decades.

\footnotetext{
* Correspondence: ejeschke@havelhoehe.de

'Havelhoehe Research Institute, Kladower Damm 221, 14089 Berlin, Germany
}

Particularly, the proportion of people aged 80 years or older will rise from $5 \%$ today to $14 \%$ in 2060 [1].

Bearing this development in mind, pharmacotherapy in an aging society is a challenge that will be faced in upcoming years. Increasing age will go hand-in-hand with the prevalence of many diseases and this will, therefore, lead to higher prescription drug consumption. According to data from German health insurance companies, in 2005 the proportion of drug users among the 
elderly was $91 \%$. Additionally, $55 \%$ of patients over age 75 produced $90 \%$ of drug-related costs [2].

While there is a broad field of research that analyzes pharmacological treatments in the middle aged population, there is a substantial knowledge gap in the study of pharmacotherapy in elderly patients [3]. This is mainly due to the fact that available data on pharmacotherapy in the elderly is widespread and older people are often excluded from trials. Even in cases where there is clinical data on the effects of pharmacology in elderly patients, prescribing patterns in primary care are often unknown, which is peculiar considering the elderly are the main users of pharmacotherapy.

One aspect that has more or less been neglected in health services research is the prescription of complementary drugs to elderly patients in primary care. The use of complementary and alternative medicine (CAM) among elderly persons is of worldwide significance and of increasing interest [4-7]. Some evidence has also shown that CAM is used for elderly patients with special conditions, like cancer $[8,9]$, hypertension [10], or mental disorders [11]. This is often the result of self-medication but it is also prescribed by physicians. For instance, $14.5 \%$ of women with cancer consulted an alternative practitioner in Australia within a span of 12 months [9]. In the elderly, concurrent use of CAM products and conventional medicines was found to be common [12].

There are only a few hints as to when, how, and in what amount physicians, particularly those related to CAM, prescribe complementary medicine drugs to elderly patients. To fill this knowledge gap, the EvaMed project was launched by physicians specializing in anthroposophic medicine (AM) [13]. AM is a medical system that was founded in the 1920s by Rudolf Steiner and Ita Wegman [14]. Apart from physical therapies like rhythmical embrocations [15], therapeutic eurythmy [16], or creative art therapies [17], AM offers a broad variety of pharmacological therapies. AM, however, is not an isolated system; it regards itself as an extension of conventional treatment, requiring the physician to combine both conventional and anthroposophic treatments to an individualized and personalized treatment regimen to stimulate the capacity of the patient for selfhealing.

Anthroposophic remedies are based on preparations of mineral, botanical, or zoological origins as well as chemically defined substances that are either undiluted or based on the homoeopathic principle of high dilution. In the field of oncology, for example, anthroposophic remedies based on mistletoe extracts are the most important drugs in Germany. According to a survey by Münstedt et al., every third GP (35\%) prefers mistletoe extracts for the treatment of cancer patients [18]. Anthroposophical pharmacotherapy also provides combined preparations. Cardiodoron $^{\circledR}$, for example, a composition of extracts from Primula officinalis and Onopordon acanthium blossoms combined with extracts from the herb Hyoscyamus niger, is frequently prescribed for cardio-respiratory coordination, such as for patients with orthostatic symptoms [19].

Implemented in the German Drug Law, AM together with homeopathy and phytotherapy are summarized as "special therapeutic directions". Note that pharmaceutical ingredients like Hypericum perforatum (St. John's wort) by means of their manufacturing may occur in all three special therapeutic directions. On the drug level, however, the classification is distinct; every CAM-related drug therapy according to the pharmaceutical preparation is assigned only to one of these directions.

To offer insight into the field of CAM-related pharmacotherapy in elderly patients, this analysis aims to investigate the prescribing patterns for this group of patients.

\section{Methods}

In total, 29 primary care physicians in Germany participated in this prospective, multicenter observational study. All were members of the EvaMed Pharmacovigilance Network, which since 2004 has aimed to evaluate complementary remedies in usual care with regard to prescribing patterns, efficacy, and safety $[13,20]$. Physicians were recruited through the German National Association of Anthroposophic Physicians (Gesellschaft Antroposophischer Ärzte in Deutschland; GAÄD). A total of 362 physicians were contacted and informed about the EvaMed Network by standard mail and, in the event of no response, four weeks later by telephone. For a physician to be eligible to participate in the study, his or her medical practice had to meet a number of technical requirements, including the presence of a special computerized patient documentation system (DocExpert, DocConcept, TurboMed, Duria, AdamedPlus, Medistar), a local area network (LAN) connection, and Microsoft Windows and Internet Explorer (i.e. as client software). A total of 38 physicians (10.5\%) fulfilled the technical requirements, gave informed consent, and agreed to participate in the EvaMed Network. Of these physicians, the 9 who specialized in paediatrics were excluded from the study. Each of the remaining 29 physicians had practised for at least five years in primary care in addition to completing training in anthroposophic medicine.

The study period lasted from January through December 2005. Data were included in the analysis if patients were at least 60 years old and had received drug treatment at least once during the study period.

During the study, participating physicians continued to follow their routine documentation procedures, recording all treatment relevant diagnoses and all 
prescriptions for each consecutive patient using their existing computerized patient documentation system. These data were exported to the QuaDoSta postgreSQLdatabase system hosted in each practice [21]. After completing each export, participating physicians used a browser-based interface to match individual diagnoses with the corresponding drugs or remedies that had been prescribed. After receiving the data sets, study investigators checked the data for completeness (e.g. matching diagnoses with remedies). If necessary, the study center phoned the physicians and asked them to supply any missing data.

Diagnoses were coded according to the 10th revision of the International Classification of Diseases (ICD-10). Prescribed drugs were documented using the German National Drug Code (German: Pharmazentralnummer; PZN). Medications were classified as anthroposophic, homoeopathic, phytotherapeutic, or conventional according to the German ABDA database (ABDA = German acronym for the Federal Confederation of German Pharmacist Associations), which contains a broad range of data on all currently available medicinal drugs and substances. 'Anthroposophic', 'homoeopathic', and 'phytotherapeutic' were defined according to the regulations of the German Drug Law and are referred to below as 'CAM remedies'. Overall medication regimens were classified as consisting of CAM remedies alone, conventional pharmaceuticals alone, or a combination of both.

The present study is based on secondary data provided by physicians. As such, the recommendations for good practice in secondary data analysis (e.g. anonymization of data on prescriptions and diagnoses) developed by the German Working Group on the Collection and Use of Secondary Data [22] were applied in full. In addition, the study was approved by the responsible data security official.

Statistical analysis was performed with SPSS 16.0 for Windows. Descriptive analysis was used to determine prescription rates. Means and standard deviations (SD) were calculated for continuous data. In cases where data were not normally distributed, medians and interquartile ranges (IQR) were reported. The two-tailed chi-square test was used to analyze differences in prescription rates and the Cochran-Armitage test was used as a measure of age-related trends in prescription rates. The KruskalWallis test was used to analyze differences in medians of prescriptions and prescribed medications among groups. The significance level was set at $\alpha=0.05$. Subgroup analyses were performed for patient gender, age (60-74 years; 75-79 years, 80 years or older), and diagnosis (ICD-10 chapters), as well as for drug type, medication regimen, physician specialization, and consultation type (first vs. follow up).

As a precursor to multivariate analysis, univariate analysis with bonferroni correction was carried out to determine factors associated with the prescription of anthroposophic remedies. We included consultation type (first vs. follow up), physician specialization, patient age and sex, ICD10-diagnoses groups, number of diagnoses, and number of prescribed remedies at admission as relevant variables in our analysis. Associations were analysed in the complete study population and across age strata.

A multiple logistic regression model was then conducted using a stepwise backward selection based on the likelihood ratio statistics. Adjusted odds ratios (AOR) and 95\% confidence intervals (CI) were calculated. The dependent variable was the prescribing of any anthroposophic remedy. Significant results of univariate analysis that were independly associated with prescribing anthroposophic remedies were included as independent variables in the logistic regression model. Patient age was introduced in the model as a continuous, centered variable. Multicollinearity and interactions between independent predictors were investigated. The HosmerLemeshow goodness-of-fit test was used to assess how well the chosen model fits the data $\left(\chi^{2}=87.16 ; d f=8\right.$; $P<0.001)$.

\section{Results}

\section{Physicians}

Of the 29 participating physicians, 21 (72\%) were GPs and 8 (28\%) were specialists (including 4 (14\%) internists). The participating physicians did not differ significantly from the overall population of physicians certified in anthroposophic treatment in Germany in $2005(\mathrm{n}=362)$ in terms of mean age $(49.1 \pm 6.1$ years vs. $47.5 \pm 6.1$ years; $P=0.175)$ or gender $(58.1 \%$ vs. $62.2 \%$ males; $P=0.662)$ and they were only slightly younger and consisted of a similar percentage of women compared to all office-based physicians in Germany (mean 52.0 years; $61.2 \%$ men) [23].

\section{Patients and prescriptions}

During the one-year study period in 2005, a total of 12 314 prescriptions for 3076 patients aged 60 years or older $(68.1 \%$ female) were included. Altogether, 2103 (68.4\%; $66.4 \%$ female) of the patients were $60-74$ years, $391(12.7 \% ; 62.9 \%$ female) were $75-79$ years, and 582 (18.9\%; $77.7 \%$ female) were 80 years or older. The median age was 69 (IQR $[65,77]$ ). Each patient had a median of 2 (IQR $[1,5]$ ) prescriptions per year.

\section{Diagnoses}

Table 1 provides a detailed overview of treatment diagnoses according to patient age and gender. In total, $23.5 \%$ of the reported diagnoses were diseases of the circulatory system, $13.9 \%$ were cancer, $10.6 \%$ were diseases of the musculoskeletal system and connective tissue, $8.1 \%$ were endocrine, nutritional and metabolic diseases, 
Table 1 Most frequent diagnoses according to age group and gender

\begin{tabular}{|c|c|c|c|}
\hline Diagnosis [ICD-10] & $\begin{array}{r}\text { Total } \\
{[\%]}\end{array}$ & $\begin{array}{r}\text { Female } \\
{[\%]}\end{array}$ & $\begin{array}{r}\text { Male } \\
{[\%]}\end{array}$ \\
\hline \multicolumn{4}{|l|}{$60-74$ years $(n=2127)$} \\
\hline Hypertensive diseases [110-115] & 25.1 & 23.3 & 28.6 \\
\hline $\begin{array}{l}\text { Malignant neoplasms, stated or presumed to be primary, of specified sites, except of lymphoid, haematopoietic, and } \\
\text { related tissue }[C 00-C 75]\end{array}$ & 19.0 & 20.8 & 15.5 \\
\hline Mood [affective] disorders [F30-F39] & 11.9 & 13.0 & 7.2 \\
\hline Dorsopathies [M40-M54] & 10.7 & 10.1 & 12.0 \\
\hline Arthropathies [M00-M25] & 9.1 & 10.1 & 7.1 \\
\hline Episodic and paroxysmal disorders* [G40-G47] & 8.3 & 9.0 & 6.8 \\
\hline Other forms of heart disease [130-152] & 8.3 & 8.1 & 8.6 \\
\hline General symptoms and signs [R50-R69] & 8.2 & 8.5 & 7.7 \\
\hline Chronic lower respiratory diseases [J40-J47] & 8.0 & 8.1 & 7.9 \\
\hline Diabetes mellitus [E10-E14] & 6.3 & 4.4 & 10.0 \\
\hline \multicolumn{4}{|l|}{$75-79$ years $(n=396)$} \\
\hline Hypertensive diseases [110-115] & 33.6 & 31.9 & 36.6 \\
\hline Other forms of heart disease [130-152] & 16.4 & 15.0 & 19.0 \\
\hline $\begin{array}{l}\text { Malignant neoplasms, stated or presumed to be primary, of specified sites, except of lymphoid, haematopoietic, and } \\
\text { related tissue }[C 00-C 75]\end{array}$ & 12.6 & 8.3 & 20.4 \\
\hline Mood [affective] disorders [F30-F39] & 10.9 & 12.6 & 7.7 \\
\hline Ischaemic heart diseases [120-125] & 10.6 & 10.2 & 11.3 \\
\hline Diabetes mellitus [E10-E14] & 10.1 & 12.2 & 6.3 \\
\hline Dorsopathies [M40-M54] & 9.8 & 11.8 & 6.3 \\
\hline Arthropathies [M00-M25] & 9.8 & 10.6 & 8.5 \\
\hline Chronic lower respiratory diseases [J40-J47] & 9.3 & 7.5 & 12.7 \\
\hline Organic, including symptomatic, mental disorders ${ }^{* *}$ [F00-F09] & 6.8 & 6.7 & 7.0 \\
\hline \multicolumn{4}{|l|}{80 years or older $(n=553)$} \\
\hline Hypertensive diseases [110-115] & 39.4 & 39.6 & 38.8 \\
\hline Other forms of heart disease [130-152] & 32.9 & 33.3 & 22.3 \\
\hline Ischaemic heart diseases [120-125] & 16.8 & 16.7 & 17.4 \\
\hline Arthropathies [M00-M25] & 15.7 & 17.6 & 9.1 \\
\hline Dorsopathies [M40-M54] & 12.8 & 12.3 & 14.9 \\
\hline Episodic and paroxysmal disorders* [G40-G47] & 12.3 & 13.0 & 9.9 \\
\hline Organic, including symptomatic, mental disorders ${ }^{* *}$ [F00-F09] & 11.6 & 11.1 & 13.2 \\
\hline Osteopathies and chondropathies [M80-M94] & 9.9 & 12.3 & 1.7 \\
\hline Chronic lower respiratory diseases [J40-J47] & 9.8 & 8.8 & 13.2 \\
\hline Mood [affective] disorders [F30-F39] & 9.4 & 9.5 & 9.1 \\
\hline $\begin{array}{l}\text { Malignant neoplasms, stated or presumed to be primary, of specified sites, except of lymphoid, haematopoietic, and } \\
\text { related tissue [C00-C75] }\end{array}$ & 9.4 & 8.6 & 12.4 \\
\hline
\end{tabular}

* including sleep disorders, ** including dementia

$7.7 \%$ were diseases of the nervous system, and $6.8 \%$ were mental and behavioural disorders. Other diseases range far behind. The most frequent single diagnoses were essential hypertension (11.1\%), breast cancer (3.5\%), heart failure (3.0\%), depression (2.6\%), Parkinson's disease (2.5\%), and chronic ischemic heart disease (2.3\%).

Every patient had an average of $3.33 \pm 3.10$ different treatment diagnoses per year (median: 2; IQR $[1,4]$ ). In total, $48.7 \%$ of patients had more than 2 diagnoses ( 3 or 4 diagnoses: $22.4 \%$, more than 4 diagnoses: $26.3 \%$ ). The number of diagnoses increased with patient age (more than 2 diagnoses: $60-74$ years: $44.2 \%$; $75-79$ years: 50.6 ; $\geq$ 80 years: $61.7 \%$ ) and was higher for women than men (more than 2 diagnoses: $50.6 \%$ vs. $44.8 \%$ ).

\section{Pharmacological therapy}

Of the 28961 medications prescribed, physicians recorded a median of 1 (IQR [1,2]) drug and remedy per patient and consultation. Every patient had a median of 4 (IQR $[2,11]$ ) medications per year. Figure 1 provides a detailed overview of the number of prescribed medications per patient during the one year study period. 


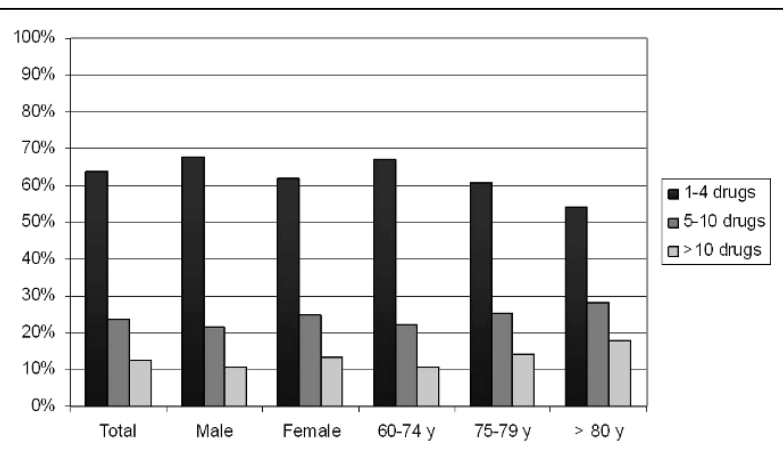

Figure 1 Number of prescribed drugs per patient and year according to gender and age group

$63.7 \%$ of the patients were prescribed 1-4 different drugs, $23.8 \%$ were prescribed $5-10$ drugs, and $12.5 \%$ of patients were prescribed more than 10 drugs per year.

Table 2 gives a detailed overview of the medication regimens prescribed by the participating physicians. In total, $30.5 \%$ of the regimens could be classified as CAM remedies alone, $54.4 \%$ as conventional pharmaceuticals alone, and $15.1 \%$ as a combination of CAM remedies and conventional pharmaceuticals. There were significant differences in medication regimen according to patient age $(P<0.001)$ and gender $(P<0.001)$, physician specialization $(P<0.001)$, consultation type $(P<0.001)$, and for various diagnoses $(P<0.001)$. For example, the proportion of the therapy regimen 'only CAM treatment' decreased significantly with patient age $(36.2 \%$; 60-74 years, $23.2 \%$; $75-79$ years, and $21.7 \%$ over 80 years; $P$ for trend $<0.001)$ and was higher in women than men $(32.7 \%$ vs. $25.3 \% ; P<0.001)$.

Table 3 provides an overview of the most frequently prescribed conventional pharmaceuticals according to age group and gender. In total, conventional pharmaceuticals accounted for $58.3 \%$ of all medications prescribed. The most frequent substances were metoprolol (beta-blocker; $2.4 \%$ of all conventional pharmaceuticals), levothyroxine sodium (thyroid hormone; 1.9\%), metamizole sodium (pyrazolone; $1.9 \%$ ), acetylsaliyciclic acid (1.6\%), enalapril (ACE inhibitor; 1.6\%), dopa and dopa derivates (anti-Parkinson drug; 1.6\%), and furosemide (diuretic; 1.4\%). Antihypertensive medication (e.g. calcium channel blockers, diuretics, beta-blockers, angiotensin converting enzyme (ACE) inhibitors, angiotensin II receptor antagonists, alpha-1 blockers, and antiadrenergic agents) accounted for $20.0 \%(\mathrm{n}=3390)$ of all conventional drugs prescribed $(11.7 \%$ of all drugs and remedies). The most frequently prescribed substances according to drug classes were as analgesics various opioids (50.9\% of all analgesics) and pyrazolone (metamizole sodium; $33.7 \%$ ), as psycholeptics benzodiazepine derivates (28.7\% of all psycholeptics) and benzodiazepine related drugs $(25.4 \%)$, as anti-dementia drugs anticholinesterases (18.0\% of all anti-dementia drugs) and memantine (13.4\%), as antidepressants amitriptyline (19.3\% of all antidepressants) and doxepin (7.5\%), as anti-Parkinson drugs dopa and dopa-derivates $(45.6 \%$ of all antiParkinson drugs) and dopamine agonists (35.1\%), and as lipid modifying agents simvastatine $(61.6 \%$ of all lipid modifying agents).

CAM remedies accounted for $41.7 \%$ of all medications prescribed (35.5\% anthroposophic, 3.3\% homeopathic, $2.9 \%$ phytotherapeutic). The proportion of CAM remedies was significantly higher for women than for men (33.2\% vs. $46.1 \% ; P<0.001$ ). Although the total number of prescribed CAM remedies remained stable, the proportion of CAM remedies decreased with patient age while conventional drugs were prescribed more often (48.1\% 60-74 years, $32.1 \%$ 75-79 years, and $30.1 \%$ over 80 years; $P$ for trend $<0.001)$. The phytopharmaceutical ginkgo biloba was the most frequently prescribed antidementia drug overall $(68.6 \%$ of all anti-dementia drugs).

Of those 124 patients who received antidementiva, 92 were given ginkgo biloba alone (74.2\%) and one patient was co-prescribed ginkgo biloba with anticholinesterases (0.8\%).

Hypericum perforatum served as a phytopharmaceutical, homeopathic or anthroposophic remedy often prescribed for depression (45.5\% of all antidepressants). Of those 184 patients who received antidepressants, 69 (37.5\%) were prescribed Hypericum perforatum alone, while 4 patients were co-prescribed Hypericum perforatum with amitriptyline (2.2\% of all depressive patients), and no patient was co-prescribed Hypericum perforatum with doxepin.

Altogether, 10271 prescriptions for a total of 976 different anthroposophic remedies were prescribed during the study. Various mistletoe preparations (e.g. Abnobaviscum abietis ${ }^{\circ}$, Abnobaviscum mali ${ }^{\circ}$, Helixor $\mathrm{P}^{\circ}$, Iscador $\left.\mathrm{P}^{\oplus}\right)$ accounted for $21.7 \%(\mathrm{n}=2233)$ of all anthroposophic remedies prescribed ( $7.7 \%$ of all drugs and remedies). In total, mistletoe was prescribed for $81.6 \%$ (413/ 506) of all patients with cancer. Other more frequent anthroposophic remedies for particular diagnoses were Cardiodoron $^{\circ}$ and Aurum/Belladonna comp. ${ }^{\circ}$ for essential hypertension, Helleborus niger e planta tota ${ }^{\circ}$ for cancer, Oleum Strophanthi forte ${ }^{\circ}$ for heart failure, Solum $\mathrm{Oil}^{\circ}$ for dorsopathies ${ }^{\oplus}$, and hypericum and various Aurum peparations for depression.

The proportion of prescribed anthroposophic medication significantly decreased with patient age $(41.4 \% 60$ 74 years, $26.7 \% 75-79$ years, and $25.2 \%$ over 80 years; $P$ for trend $<0.001$ ) and was higher for female than male patients $(37.7 \%$ vs. $30.5 \%, P<0.001)$. After bonferroni correction in univariate analysis, consultation type, 
Table 2 Therapy regimen according to consultation type, physician specialization, patient age, gender, and diagnosis

\begin{tabular}{|c|c|c|c|c|c|c|c|}
\hline & \multirow{2}{*}{$\begin{array}{c}\text { Total } \\
\mathrm{N}\end{array}$} & \multicolumn{2}{|c|}{$\begin{array}{l}\text { Only CAM } \\
\text { treatment }\end{array}$} & \multicolumn{2}{|c|}{$\begin{array}{l}\text { CAM and } \\
\text { conventional } \\
\text { treatment } \\
\text { combined }\end{array}$} & \multicolumn{2}{|c|}{$\begin{array}{c}\text { Only } \\
\text { conventional } \\
\text { treatment }\end{array}$} \\
\hline & & $\mathrm{n}$ & $\%$ & $\mathbf{n}$ & $\%$ & $\mathbf{n}$ & $\%$ \\
\hline Total & 12314 & 3758 & 30.5 & 1858 & 15.1 & 6698 & 54.4 \\
\hline \multicolumn{8}{|l|}{ Consultation type } \\
\hline First & 1845 & 664 & 36.0 & 139 & 7.5 & 1042 & 56.5 \\
\hline Follow-up & 10469 & 3094 & 29.6 & 1719 & 16.4 & 5656 & 54.0 \\
\hline \multicolumn{8}{|l|}{ Physician specialization } \\
\hline GP & 7956 & 2376 & 29.9 & 1161 & 14.6 & 4419 & 55.5 \\
\hline Internal medicine & 2527 & 972 & 38.5 & 427 & 16.9 & 1128 & 44.6 \\
\hline Other & 1831 & 410 & 22.4 & 270 & 14.7 & 1151 & 62.9 \\
\hline \multicolumn{8}{|l|}{ Age (y) } \\
\hline $60-74$ & 7320 & 2648 & 36.2 & 1134 & 15.5 & 3538 & 48.3 \\
\hline $75-79$ & 1762 & 409 & 23.2 & 239 & 13.6 & 1114 & 63.2 \\
\hline$>80$ & 3232 & 701 & 21.7 & 485 & 15.0 & 2046 & 63.3 \\
\hline \multicolumn{8}{|l|}{ Sex } \\
\hline male & 3567 & 901 & 25.3 & 513 & 14.4 & 2153 & 60.4 \\
\hline female & 8747 & 2857 & 32.7 & 1345 & 15.4 & 4545 & 52.0 \\
\hline \multicolumn{8}{|l|}{ Diagnosis [ICD-10] } \\
\hline Diseases of the circulatory system [100-199] & 2835 & 563 & 19.9 & 424 & 15.0 & 1848 & 65.2 \\
\hline Neoplasms [C00-D48] & 1380 & 856 & 62.0 & 137 & 9.9 & 387 & 28.0 \\
\hline Diseases of the musculoskeletal system and connective tissue [M00-M99] & 1211 & 443 & 36.6 & 206 & 17.0 & 562 & 46.4 \\
\hline Endocrine, nutritional, and metabolic diseases [E00-E90] & 1103 & 148 & 13.4 & 141 & 12.8 & 814 & 73.8 \\
\hline Diseases of the nervous system [G00-G99] & 1058 & 189 & 17.9 & 119 & 11.2 & 750 & 70.9 \\
\hline Mental and behavioural disorders [F00-F99] & 901 & 260 & 28.9 & 126 & 14.0 & 515 & 57.2 \\
\hline Diseases of the digestive system [K00-K93] & 763 & 220 & 28.8 & 147 & 19.3 & 396 & 51.9 \\
\hline Diseases of the respiratory system [J00-J99] & 745 & 308 & 41.3 & 155 & 20.8 & 282 & 37.9 \\
\hline Symptoms, signs, and abnormal clinical and laboratory findings [R00-R99] & 695 & 215 & 30.9 & 133 & 19.1 & 347 & 49.9 \\
\hline Diseases of the genitourinary system [N00-N99] & 386 & 124 & 32.1 & 50 & 13.0 & 212 & 54.9 \\
\hline Diseases of the skin and subcutaneous tissue [L00-L99] & 376 & 136 & 36.2 & 67 & 17.8 & 173 & 46.0 \\
\hline Injury, poisoning, and certain other consequences of external causes [S00-T98] & 263 & 80 & 30.4 & 35 & 13.3 & 148 & 56.3 \\
\hline Certain infectious and parasitic diseases [A00-B99] & 260 & 71 & 27.3 & 62 & 23.8 & 127 & 48.8 \\
\hline Diseases of the eye and adnexa [H00-H59] & 103 & 50 & 48.5 & 19 & 18.4 & 34 & 33.0 \\
\hline Other $\mathrm{n}<100$ & 235 & 95 & 40.4 & 37 & 15.7 & 103 & 43.8 \\
\hline
\end{tabular}

physician specialization, and the following diagnoses were also found to be significant: hypertensive diseases, cancer, arthropathies, chronic lower respiratory diseases, diabetes mellitus, episodic and paroxysmal disorders, ischemic heart disease, extrapyramidal and movement disorders, dorsopathies, metabolic disorders, and disorders of the thyroid gland. Diagnoses with a proportion of anthroposophic medication over $60 \%$ were neoplasms $(71.3 \%)$, as well as diseases of the eye and adnexa (68.6\%), and less than 15\% endocrine, nutritional, and metabolic disorders (14.7\%). For diseases of the circulatory system, the most frequent disorders, only $24.4 \%$ of the drugs and remedies prescribed were anthropsophic medication.

Table 4 shows the adjusted odds ratio (AOR) for the most frequent diagnoses and other factors associated with being prescribed an anthroposophic remedy. Patient age and gender, as well as physician specialization, consultation type, and diagnoses, had an impact on the choice of remedy prescribed. The AOR for receiving an anthroposophic remedy was significantly greater than 1 for patients having their first consultation $(A O R=$ 1.65; CI: $1.52-1.79$ ), treatment by an internist (AOR = 1.49; CI: $1.40-1.58)$, female patients $(\mathrm{AOR}=1.35$; $\mathrm{CI}$ : 
Table 3 Most frequent conventional drugs according to age group and gender

\begin{tabular}{|c|c|c|c|c|c|c|c|c|c|c|c|c|}
\hline \multirow[t]{3}{*}{ Medication [ATC classification] } & \multicolumn{2}{|c|}{ Total } & \multicolumn{4}{|c|}{ Gender } & \multicolumn{6}{|c|}{ Age (y) } \\
\hline & \multirow[b]{2}{*}{$\mathbf{N}$} & \multicolumn{2}{|c|}{ Male } & \multicolumn{3}{|c|}{ Female } & \multicolumn{2}{|c|}{$60-74$} & \multicolumn{2}{|c|}{$75-79$} & \multicolumn{2}{|c|}{$>80$} \\
\hline & & $\%$ & $\mathbf{n}$ & $\%$ & $\mathbf{n}$ & $\%$ & $\mathrm{n}$ & $\%$ & $\mathbf{n}$ & $\%$ & $\mathbf{n}$ & $\%$ \\
\hline Total & 16910 & 100.0 & 5661 & 100.0 & 11249 & 100.0 & 9303 & 100.0 & 2795 & 100.0 & 4812 & 100.0 \\
\hline $\begin{array}{l}\text { AGENTS ACTING ON THE RENIN-ANGIOTENSIN SYSTEM } \\
\text { [C09] }\end{array}$ & 1218 & 7.2 & 469 & 8.3 & 749 & 6.7 & 714 & 7.7 & 208 & 7.4 & 296 & 6.2 \\
\hline ANALGESICS [N02] & 945 & 5.6 & 298 & 5.3 & 647 & 5.8 & 571 & 6.1 & 78 & 2.8 & 296 & 6.2 \\
\hline PSYCHOLEPTICS [N05] & 823 & 4.9 & 281 & 5.0 & 541 & 4.8 & 400 & 4.3 & 144 & 5.2 & 279 & 5.8 \\
\hline DIURETICS [C03] & 795 & 4.7 & 266 & 4.7 & 529 & 4.7 & 301 & 3.2 & 157 & 5.6 & 337 & 7.0 \\
\hline BETA BLOCKING AGENTS [CO7] & 740 & 4.4 & 275 & 4.9 & 465 & 4.1 & 453 & 4.9 & 116 & 4.2 & 171 & 3.6 \\
\hline PSYCHOANALEPTICS [N06] & 711 & 4.2 & 242 & 4.3 & 469 & 4.2 & 329 & 3.5 & 135 & 4.8 & 247 & 5.1 \\
\hline CARDIAC THERAPY [C01] & 648 & 3.8 & 205 & 3.6 & 358 & 3.2 & 215 & 2.3 & 116 & 4.1 & 317 & 6.6 \\
\hline ANTI-PARKINSON DRUGS [N04] & 643 & 3.8 & 363 & 6.4 & 280 & 2.5 & 296 & 3.2 & 153 & 5.5 & 194 & 4.0 \\
\hline ANTITHROMBOTIC AGENTS [B01] & 559 & 3.3 & 245 & 4.3 & 314 & 2.8 & 205 & 2.2 & 117 & 4.2 & 237 & 4.9 \\
\hline $\begin{array}{l}\text { ANTIINFLAMMATORY AND ANTIRHEUMATIC PRODUCTS } \\
\text { [M01] }\end{array}$ & 552 & 3.3 & 148 & 2.6 & 404 & 3.6 & 316 & 3.4 & 78 & 2.8 & 158 & 3.3 \\
\hline DRUGS FOR ACID RELATED DISORDERS [A02] & 506 & 3.0 & 150 & 2.6 & 356 & 3.2 & 300 & 3.2 & 57 & 2.0 & 149 & 3.1 \\
\hline CALCIUM CHANNEL BLOCKERS [C08] & 489 & 2.9 & 191 & 3.4 & 298 & 2.6 & 208 & 2.2 & 125 & 4.5 & 156 & 3.2 \\
\hline THYROID THERAPY [H03] & 440 & 2.6 & 63 & 1.1 & 377 & 3.4 & 319 & 3.4 & 61 & 2.2 & 60 & 1.2 \\
\hline DRUGS FOR OBSTRUCTIVE AIRWAY DISEASES [R03] & 438 & 2.6 & 171 & 3.0 & 267 & 2.4 & 226 & 2.4 & 100 & 3.6 & 112 & 2.3 \\
\hline DRUGS USED IN DIABETES [A10] & 426 & 2.5 & 167 & 3.0 & 259 & 2.3 & 274 & 2.9 & 76 & 2.7 & 76 & 1.6 \\
\hline MINERAL SUPPLEMENTS [A12] & 422 & 2.5 & 79 & 1.4 & 343 & 3.0 & 254 & 2.7 & 44 & 1.6 & 124 & 2.6 \\
\hline ANTIBIOTICS [J01] & 366 & 2.2 & 115 & 2.0 & 251 & 2.2 & 205 & 2.2 & 64 & 2.3 & 97 & 2.0 \\
\hline LIPID MODIFYING AGENTS [C10] & 333 & 2.0 & 141 & 2.5 & 192 & 1.7 & 237 & 2.5 & 54 & 1.9 & 42 & 0.9 \\
\hline Other $n<300$ & 5856 & 34.6 & 1792 & 31.7 & 4150 & 36.9 & 3480 & 37.4 & 912 & 32.6 & 1464 & 30.4 \\
\hline
\end{tabular}

1.27-1.43), cancer $(\mathrm{AOR}=4.54 ; \mathrm{CI}: 4.12-4.99)$, arthropathies $(\mathrm{AOR}=1.36 ; \mathrm{CI}: 1.19-1.55)$, or dorsopathies $(\mathrm{AOR}=1.34 ; \mathrm{CI}: 1.16-1.55)$. The likelihood of being prescribed an anthroposophic remedy was especially low for patients with hypertensive diseases $(\mathrm{AOR}=0.36$; $\mathrm{CI}$ : 0.32-0.39), diabetes mellitus (AOR =0.17; CI: 0.14-0.22), or metabolic disorders $(\mathrm{AOR}=0.17$; $\mathrm{CI}$ : 0.13-0.22). The interactions between hypertensive disease and age, as well as extrapyramidal and movement disorders and age, were found to be statistically significant (see Figure 2 for the odds ratios in the different age strata) and were included in the model. In the case of hypertensive disease and extrapyramidal and movement disorders, the likelihood of being prescribed an anthroposophic remedy increased with age.

\section{Discussion}

\section{Diagnoses}

In accordance with the findings of Cheung et al., the most common conditions were chronic diseases [24]. Most of the patients in our cohort were treated for hypertension, cancer, depression, dorsopathies, and arthropathies. Hypertension, ischemic heart disease, and other forms of heart disease (i.e. heart failure) were the primary reasons patients 80 years and older visited a physician in our study. These diseases are also the main reasons patients aged 80 years or older are treated in conventional settings in Germany [25]. Compared to elderly patients treated by conventional physicians, the patients in this present study showed a lower proportion of diseases associated with a modern lifestyle, such as disorders of lipoprotein metabolism and diabetes mellitus $[25,26]$. This might be attributed to a higher educational level among patients treated by anthroposophic physicians, resulting in a more health-conscious lifestyle. As Unkelbach et al. has shown, patients of conventional and anthroposophic physicians in Germany are comparable in many aspects (e.g. age, proportion suffering from a chronic disease), but anthroposophic patients are more often female, a higher proportion of patients have a university degree, and a lower proportion are smokers or are overweight [27]. Other studies found CAM users tended to be younger and more educated and fewer are hypertensive or report, for example, arthritis, depression/anxiety [4,28], or pain [29].

Due to the fact that AM is well known for pharmacotherapeutic options, like mistletoe-preparations for adjuvant treatment of cancer, it is not surprising that 
Table 4 Multivariate logistic regression: factors associated with anthroposophic remedies

\begin{tabular}{|c|c|c|}
\hline Factor & AOR $(95 \% \mathrm{Cl})$ & \\
\hline \multicolumn{3}{|l|}{ Consultation type } \\
\hline Follow-up & 1 & \\
\hline First & $1.65(1.52-1.79)^{*}$ & \\
\hline \multicolumn{3}{|l|}{ Physician specialization } \\
\hline GP & 1 & \\
\hline Internal medicine & & $1.49(1.40-1.58)^{*}$ \\
\hline Other & $0.76(0.70-0.84)^{*}$ & \\
\hline Age $(y)^{* *}$ & & $0.97(0.97-0.98)^{*}$ \\
\hline \multicolumn{3}{|l|}{ Sex } \\
\hline male & 1 & \\
\hline female & $1.35(1.27-1.43)^{*}$ & \\
\hline \multicolumn{3}{|l|}{ Diagnosis (groups) } \\
\hline Hypertensive diseases [110-115] & $0.36(0.32-0.39)^{*}$ & \\
\hline $\begin{array}{l}\text { Malignant neoplasms, stated or presumed to be primary, of specified sites, except of } \\
\text { lymphoid, haematopoietic, and related tissue [CO0-C75] }\end{array}$ & $4.54(4.12-4.99)^{*}$ & \\
\hline Malignant neoplasms of ill-defined, secondary, and unspecified sites [C76-C80] & $2.90(2.54-3.30)^{*}$ & \\
\hline Arthropathies [M00-M25] & $1.36(1.19-1.55)^{*}$ & \\
\hline Chronic lower respiratory diseases [J40-J47] & $0.59(0.50-0.69)^{*}$ & \\
\hline Diabetes mellitus [E10-E14] & $0.17(0.14-0.22)^{*}$ & \\
\hline Episodic and paroxysmal disorders [G40-G47] & $0.53(0.45-0.63)^{*}$ & \\
\hline Ischaemic heart diseases [120-125] & $0.71(0.60-0.83)^{*}$ & \\
\hline Extrapyramidal and movement disorders [G20-G26] & $0.46(0.37-0.58)^{*}$ & \\
\hline Dorsopathies [M40-M54] & $1.34(1.16-1.55)^{*}$ & \\
\hline Metabolic disorders [E70-E90] & $0.17(0.13-0.22)^{*}$ & \\
\hline Disorders of thyroid gland [E00-E07] & $0.54(0.45-0.64)^{*}$ & \\
\hline \multicolumn{3}{|l|}{ Interaction terms } \\
\hline Hypertensive diseases [110-115]* age & $1.03(1.02-1.04)^{*}$ & \\
\hline Extrapyramidal and movement disorders [G20-G26] * age & $1.04(1.02-1.07)^{*}$ & \\
\hline
\end{tabular}

* OR significant different from $1 ;{ }^{* *}$ continuous centered variable

our study counted for more patients with cancer in the present study cohort [30-32]. This also applies to depression because visiting an anthroposophic physician has shown specific benefits in terms of quality of life for patients suffering from depression [33]. However, this does not directly yield a higher prescription rate of AM drugs. Particularly in the field of depression, our physicians also follow the trend of prescribing herbal remedies, like St. John's wort, which are not directly linked to AM.

A study from Canada has shown that as patients age, multimorbidity plays an increasingly important role in primary care with a prevalence of $60 \%$ among people aged 55 to 74 [34]. According to van den Akker et al., male patients aged 80 and over had a mean of 3.25 diagnoses per year, whereas female patients had a mean of 3.57 [35]. Although our cohort was slightly younger (aged 60 and older), we found a comparable value of 3.33 diagnoses. Unsurprisingly and in accordance with other findings, the percentage of patients with comorbidity increased with older age and was higher for female patients [35].

\section{Pharmacological therapy}

As already stated, we found an increment in medication directly related to the number of diagnoses. According to Laux et al., this interrelationship is mainly influenced by age and, to a lesser extend, by gender [36]. In the Slone survey, which evaluated the pattern of medication use in the ambulatory adult population of the United States, 23\% of patients aged 65 years and over took 5 or more drugs, whereas $12 \%$ took more than 10 drugs within one week [37]. In contrast to our study, they also included OTC-medications in their calculations. Another study, which evaluated characteristics of outpatient prescriptions for the elderly in Taiwan, with an average age of 78 years, found that $84 \%$ of the observed population took 5 or more drugs per year [38]. These findings strongly differ from our results; the number of prescribed different drugs per patient and year was 


\section{OR}

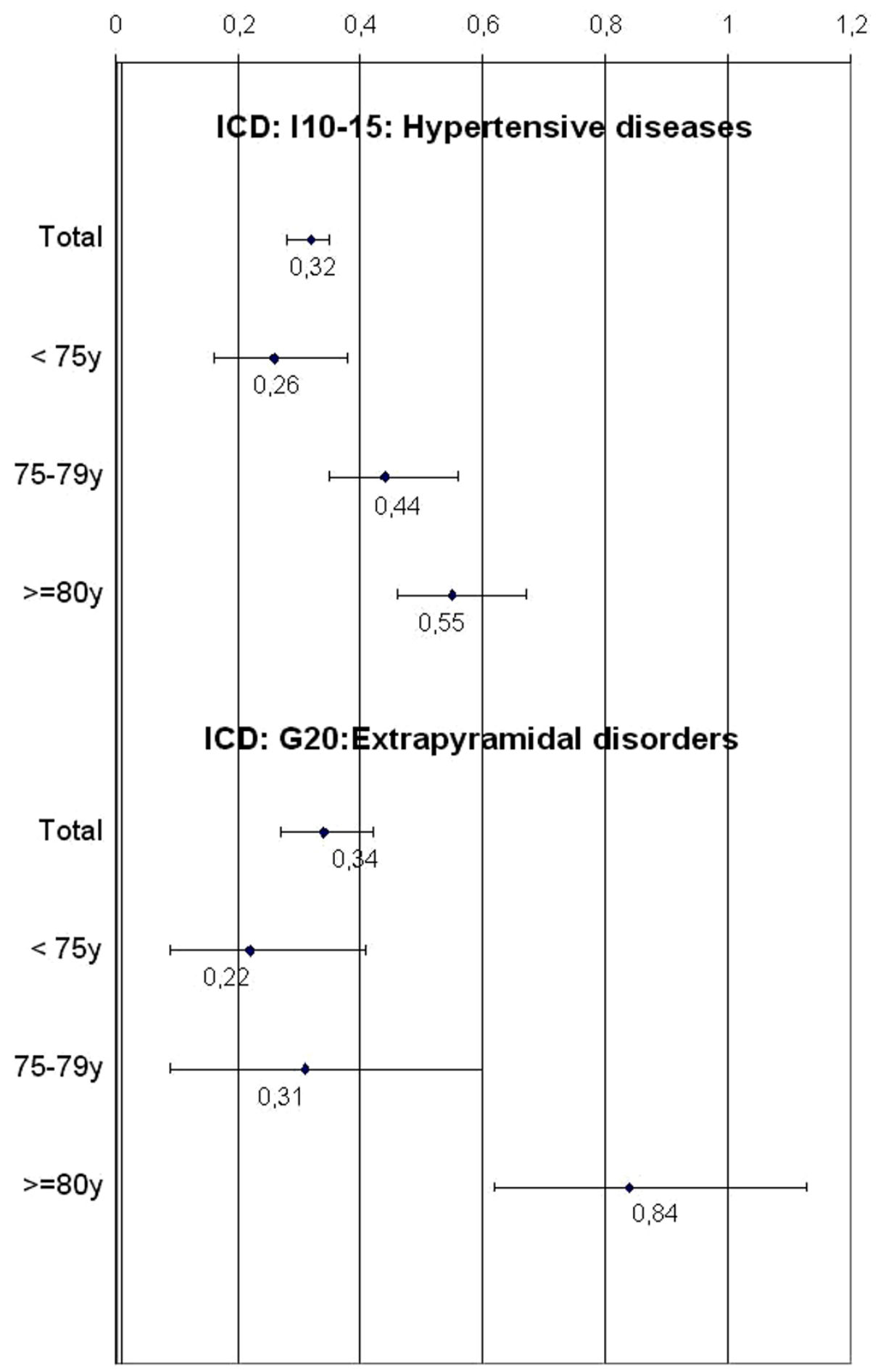

Figure 2 Odds ratios for the use of anthroposophic remedies for hypertensive disease and extrapyramidal and movement disorders stratified by age groups 
greater than 5 for only $36 \%$ of the patients and only $13 \%$ took more than 10 drugs per year. Although some factors, like the occurrence of polypharmacy, were more likely in female patients and in older patients $[37,39]$, one has to be aware that a comparison of results has to take into account the different healthcare settings and policies in which the studies were conducted.

In the field of anthroposophic medicine, pharmacological treatment is based on an integrative concept that combines conventional and CAM approaches depending on the disease and it is carried out on a patient-bypatient basis. Regardless of diagnosis, CAM remedies alone were prescribed in $31 \%$ of cases, conventional pharmaceuticals alone in $54 \%$ of cases, and a combination of CAM remedies and conventional pharmaceuticals in $15 \%$ of cases. The likelihood of receiving CAM remedies alone was highest for patients with neoplasms (62\% of all prescriptions for this group of patients) and lowest for patients with endocrine, nutritional, and metabolic disorders (13\%). It is interesting to note that CAM medications were mainly prescribed for patients with cancer and dementia, whereas the majority of patients with cardiovascular and metabolic disorders were prescribed conventional medications. This is in accordance with a previous analysis [13]; however, there is no direct explanation for this trend. One hypothesis is that no additional treatment is used for diseases that can be controlled with conventional treatment, whereas in terms of cancer, for example, patients and physicians more often seek an additional treatment.

Of course, these observations do not infer that conditions like cancer are not conventionally treated (e.g. by chemotherapy or surgery). In such cases, AM is prescribed in addition to conventional treatment sometimes over a longer period of time [40]. Mistletoe in this respect was the most frequently prescribed anthroposophic remedy. These findings partially confirm those reported in a study by Hamre et al., who also found high prescription rates for anthroposophic remedies in patients with cancer [41]. According to a recently published review, supportive mistletoe therapy seems safe and particularly beneficial for the quality of life of adult patients with solid tumours [30]. However, anthroposophic remedies were also prescribed quite frequently for dorsopathies alone or as a substitute for conventional remedies, showing an improvement in healthrelated quality of life and long-term stabilization [42]. For elderly patients with depression, various Hypericum and Aurum preparations were frequently prescribed. In accordance with the results of an earlier study, anthroposophic remedies, such Cardiodoron ${ }^{\circ}$ and Aurum/Belladonna comp..$^{\circ}$, were frequently prescribed for hypertension, mainly as adjuncts to classic antihypertensive therapy most likely as a way to stimulate and harmonize the rhythmic system and to assist the body in regulating blood pressure with its own resources $[19,43]$.

Patient gender was associated with significant differences in prescription rates in the present study. This is in accordance with the results of several studies, which found that gender had an influence on the rate at which different medications were prescribed for adults and the female sex was a predictor of CAM use in the elderly [44-46]. The present study showed that older patients are less likely to receive an anthroposophic remedy. Compared to GPs, internists prescribed anthroposophic remedies more often to patients and issued a significantly larger number of conventional and CAM medications per patient. This may be attributed to a tendency among patients to seek help from specialists in cases of severe disease.

With regard to conventional drugs, only minor differences were observed in prescription rates in the present study compared to those in the German Drug Prescription Report (Arzneimittelverordnungsreport) from 2006, an annual publication listing, among other data, of the proportion of prescriptions most frequently issued in Germany [47]. Indeed, in the present study, patients were most likely to receive medication for hypertension, followed by analgesics, psycholeptics, psychoanaleptics, and anti-Parkinson drugs.

The successful treatment of hypertension in elderly patients seems to be the most important drug therapy that reduces the agglomeration of morbidity at the end of life as shown in the HYVET-trial (Hypertension in the Very Elderly Trial) $[48,49]$. Our findings suggest that such patients are mainly treated with ACE-antagonists and diuretics. While the amount of diuretics increased with age, the amount of beta-blockers and ACE-inhibitors decreased. In accordance with other studies, in younger populations we were able to show that male patients were more likely to be prescribed an ACE-antagonist [50,51]. Altogether, hypertension was treated in accordance with the German guidelines. We give a more detailed analysis of hypertensive treatment elsewhere [43].

Another important condition is dementia. In our setting, Ginkgo biloba is the most frequently prescribed complementary drug for dementia. The appraisal of evidence for the treatment of dementia is inconsistent [52]. One of the latest studies showed that ginkgo is an effective adjuvant treatment option for elderly patients with mild cognitive impairment [53], whereas the German Institute for Quality and Efficiency in Health Care (IQWIG) found only a benefit for the $240 \mathrm{mg}$ preparation and criticized the heterogeneity of the study results [54]. However, German GPs vote ginkgo preparations for dementia as equally effective as anticholinesterases and memantine [55]. 
With regard to mental disorders in non-institutionalized elderly people, St. John's wort (Hypericum perforatum) is the most often prescribed antidepressant followed by amitriptylin and doxepin [56]. We were able to confirm these results in our primary care network. Also, other age related diseases like Parkinson's disease showed similar prescribing patterns found in other studies with a strong increase in male patients and patients aged 70 years and older [57-59].

\section{Implications for practice and policy}

The provision of CAM in primary care still needs further education and information from primary care health professionals about its potential and limitations, particularly when combining CAM remedies with conventional drugs. The chronological dimension of pharmacotherapy in the treatment of elderly patients and the occurrence of critical combinations is a topic of notably high interest to health services research. Although we did not find a significant amount of such events, our network offers possibilities to further research this topic. In addition, the associations between AM prescribing and factors like age, sex, consultation type, and diagnoses do not, to our knowledge, have a correlation in other prescription studies in primary care and should also be investigated more closely. Finally, the use of over-the-counter (OTC) medications by elderly patients is a field of interest. With only limited data on the use of CAM and OTC drugs in the elderly, physicians should record their use systematically, which would make them available for research in settings like this one.

\section{Limitations}

The present study has some limitations. Firstly, although physician prescribing data were subjected to an internal review as described above, coding inaccuracies cannot be ruled out entirely. In contrast to other methods of conducting epidemiological surveys for prescribing patterns in primary care, QuaDoSta is linked to the existing computerized patient documentation systems of physicians and can be incorporated fully into their daily routines, avoiding typical biases, such as missing data or double entries. Although such an approach may not have an impact on external validity, it can increase the internal validity of data [22]. According to Himmel (2006), we nevertheless can assume that relevant data like patient age, gender, and prescriptions are sufficiently documented by the physicians and that it is possible to use routine data for identification and classification of therapeutic actions, as well as for quality assurance in ambulatory patient care [60]. Secondly, additional data on specific diagnoses, such as information on disease severity and duration or the impact of these factors on the observed prescribing patterns, were unavailable. Thirdly, we were unable to obtain data on the subsequent medication use of patients who decided to switch physicians; similarly, no data were available for cases in which physicians provided patients with a referral for treatment by a specialist or hospital. Up to now, we also were not effectual in implementing our technology in a comparison group of conventional physicians. Finally, data on patient self-medication with CAM remedies or OTC drugs were unavailable. This may explain why only $36 \%$ of patients in this study took more than 5 medications while the numbers reported in the literature differ significantly.

\section{Conclusion}

This study of a large sample of elderly people undergoing anthroposophic primary care in Germany is the first to provide a consecutive and systematic overview of pharmacotherapy in everyday conditions. During the 12-month study period, anthroposophic remedies accounted for $36 \%$ of all medications prescribed. Regardless of diagnosis, the likelihood of receiving an anthroposophic remedy was higher for female patients, patients having their first consultation, and patients treated by an internist. Cancer, arthropathies, and dorsopathies were the diagnoses for which anthroposophic remedies were prescribed most frequently. However, the likelihood of being prescribed an anthroposophic remedy decreased with patient age and was especially low for patients with hypertensive diseases, diabetes mellitus, or metabolic disorders.

The findings show that physicians who practice anthroposophic medicine prescribe both conventional and complementary medicine, thus taking an integrative approach. Our study may facilitate further CAMresearch on indications of, for example, dementia or adverse drug reactions in the elderly.

\section{Acknowledgements}

The EvaMed network was supported by grants from the Software AG Foundation, Wala Heilmittel $\mathrm{GmbH}$, and Weleda AG. The sponsors had no influence on the design or implementation of the study, the collection, management, or analysis of data or the preparation, review, or approval of the manuscript. We would also like to thank Katie Renaud for editing the English version of this manuscript. Finally, we would like to express our special gratitude to all physicians participating in the EvaMed network.

\section{Author details}

${ }^{1}$ Havelhoehe Research Institute, Kladower Damm 221, 14089 Berlin, Germany. ${ }^{2}$ Center of Integrative Medicine, University of Witten/Herdecke, GerhardKienle-Weg 4, 58313 Herdecke, Germany. ${ }^{3}$ Institute for General Practice and Family Medicine, University of Witten/Herdecke, Alfred-Herrhausen-Str. 50, 58448 Witten, Germany. ${ }^{4}$ Deutsches Zentrum für Neurodegenerative Erkrankungen e.V. (DZNE) in cooperation with Witten/Herdecke University, Stockumer Str. 10, 58453 Witten, Germany. ${ }^{5}$ Institute for Social Medicine, Epidemiology and Health Economics, Charité University Medical Centre, 10117 Berlin, Germany.

\section{Authors' contributions}

EJ participated in the design of the study, acquisition of data, performed the statistical analysis, and drafted the manuscript. TO made substantial 
contribution to the interpretation of data and statistical analysis. MT participated in the acquisition of data. HCV, AB, MK, MT, and CMW helped with the interpretation of the data, drafting, and critical revision of the manuscript. HM conceived of the study and participated in its design and coordination. MK, CMW, SNW, and HM have given final approval for the version to be published. All authors read and approved the final manuscript.

\section{Competing interests}

The authors declare that they have no competing interests.

Received: 26 February 2010 Accepted: 21 July 2010

Published: 21 July 2010

\section{References}

1. Statistisches Bundesamt: Bevölkerung Deutschlands bis 2060. 12. koordinierte Bevölkerungsvorausberechnung. Wiesbaden 2009.

2. Glaeske G, Jahnsen K: GEK-Arzneimittel-Report 2007: Auswertungsergebnisse der GEK-Arzneimitteldaten aus den Jahren 2005 - 2006. Sankt Augustin: Asgard-Verl. Hippe: GEK-Gmünder Ersatzkasse 2007, vol. GEK-Edition Band 59

3. Van Spall HG, Toren A, Kiss A, Fowler RA: Eligibility criteria of randomized controlled trials published in high-impact general medical journals: a systematic sampling review. JAMA 2007, 297(11):1233-1240.

4. Astin JA, Pelletier KR, Marie A, Haskell WL: Complementary and alternative medicine use among elderly persons: one-year analysis of a Blue Shield Medicare supplement. J Gerontol A Biol Sci Med Sci 2000, 55(1):M4-9.

5. Najm W, Reinsch S, Hoehler F, Tobis J: Use of complementary and alternative medicine among the ethnic elderly. Altern Ther Health Med 2003, 9(3):50-57.

6. Zeilmann CA, Dole EJ, Skipper BJ, McCabe M, Low Dog T, Rhyne RL: Use of herbal medicine by elderly Hispanic and non-Hispanic white patients. Pharmacotherapy 2003, 23(4):526-532.

7. Zhang AL, Xue CC, Lin V, Story DF: Complementary and alternative medicine use by older Australians. Ann N Y Acad Sci 2007, 1114:204-215.

8. Hana G, Bar-Sela G, Zhana D, Mashiach T, Robinson E: The use of complementary and alternative therapies by cancer patients in northern Israel. Isr Med Assoc J 2005, 7(4):243-247.

9. Sibbritt D, Adams J, Easthope G, Young A: Complementary and alternative medicine (CAM) use among elderly Australian women who have cancer. Support Care Cancer 2003, 11(8):548-550.

10. Bell RA, Suerken CK, Grzywacz JG, Lang W, Quandt SA, Arcury TA: CAM use among older adults age 65 or older with hypertension in the United States: general use and disease treatment. J Altern Complement Med 2006, 12(9):903-909.

11. Grzywacz JG, Suerken CK, Quandt SA, Bell RA, Lang W, Arcury TA: Older adults' use of complementary and alternative medicine for mental health: findings from the 2002 National Health Interview Survey. J Altern Complement Med 2006, 12(5):467-473.

12. Elmer GW, Lafferty WE, Tyree PT, Lind BK: Potential interactions between complementary/alternative products and conventional medicines in a Medicare population. Ann Pharmacother 2007, 41(10):1617-1624.

13. Jeschke E, Ostermann T, Tabali M, Bockelbrink A, Witt CM, Willich SN, Matthes $\mathrm{H}$ : Diagnostic profiles and prescribing patterns in everyday anthroposophic medical practice-a prospective multi-centre study. Forsch Komplementmed 2009, 16(5):325-333.

14. Steiner R, Wegmann I: Extending practical medicine: fundamental principles based on the science of the spirit. GA 27 Bristol: Rudolf Steiner Press 2000, 1-144.

15. Ostermann T, Blaser G, Bertram M, Michalsen A, Matthiessen PF, Kraft K: Effects of rhythmic embrocation therapy with solum oil in chronic pain patients: a prospective observational study. Clin J Pain 2008, 24(3):237-243.

16. Bussing A, Ostermann T, Majorek M, Matthiessen PF: Eurythmy Therapy in clinical studies: a systematic literature review. BMC Complement Altern Med 2008, 8:8.

17. Hamre HJ, Witt CM, Glockmann A, Ziegler R, Willich SN, Kiene H: Anthroposophic art therapy in chronic disease: a four-year prospective cohort study. Explore (NY) 2007, 3(4):365-371.

18. Munstedt K, Entezami A, Kullmer U: [Oncologic mistletoe therapy: physicians' use and estimation of efficiency]. Dtsch Med Wochenschr 2000, 125(41):1222-1226.
19. Cysarz D, Heckmann C, Kummell HC: [The effects of Cardiodoron on cardio-respiratory coordination-a literature review]. Forsch Komplementarmed Klass Naturheilkd 2002, 9(5):292-297.

20. Jeschke E, Ostermann T, Luke C, Tabali M, Kroz M, Bockelbrink A, Witt CM, Willich SN, Matthes H: Remedies containing Asteraceae extracts: a prospective observational study of prescribing patterns and adverse drug reactions in German primary care. Drug Saf 2009, 32(8):691-706.

21. Jeschke E, Luke C, Ostermann T, Tabali M, Hubner J, Matthes H: [Prescribing practices in the treatment of upper respiratory tract infections in anthroposophic medicine]. Forsch Komplementmed 2007, 14(4):207-215

22. AGENS: Good practice of secondary data analysis, first revision]. Gesundheitswesen 2008, 70(1):54-60.

23. Kassenärztliche Bundesvereinigung: Grunddaten zur vertragsärztlichen Versorgung 2008. [http://www.zi-berlin.de/morbilitaetsanalyse/downloads/ ADT-Panel-version3.pdf].

24. Cheung CK, Wyman JF, Halcon LL: Use of complementary and alternative therapies in community-dwelling older adults. J Altern Complement Med 2007, 13(9):997-1006.

25. Grobe TG, Dörning H, Schwartz FW: GEK-Report ambulant-ärztliche Versorgung 2008. St. Augustin: Asgard-Verlag 2007, GEK-Edition Band 67 edn.

26. Kerek-Bodden $\mathrm{H}$, Koch $\mathrm{H}$, Brenner $\mathrm{G}$, Flatten $\mathrm{G}$ : [Diagnostic spectrum and treatment requirements of general practice clients. Results of the ADT Panel of the Central Institute of National Health Insurance Management]. Z Arztl Fortbild Qualitatssich 2000, 94(1):21-30.

27. Unkelbach $\mathrm{R}, \mathrm{Abholz} \mathrm{HH}$ : [Differences between patients of conventional and anthroposophic family physicians]. Forsch Komplementmed 2006, 13(6):349-355.

28. Cherniack EP, Senzel RS, Pan CX: Correlates of use of alternative medicine by the elderly in an urban population. J Altern Complement Med 2001, 7(3):277-280.

29. Dello Buono M, Urciuoli O, Marietta P, Padoani W, De Leo D: Alternative medicine in a sample of 655 community-dwelling elderly. J Psychosom Res 2001, 50(3):147-154.

30. Melzer J, Iten F, Hostanska K, Saller R: Efficacy and safety of mistletoe preparations (Viscum album) for patients with cancer diseases. A systematic review. Forsch Komplementmed 2009, 16(4):217-226.

31. Carlsson M, Arman M, Backman M, Flatters U, Hatschek T, Hamrin E: A Fiveyear Follow-up of Quality of Life in Women with Breast Cancer in Anthroposophic and Conventional Care. Evid Based Complement Alternat Med 2006, 3(4):523-531.

32. Legnani W: Mistletoe in conventional oncological practice: exemplary cases. Integr Cancer Ther 2008, 7(3):162-171.

33. Hamre HJ, Witt CM, Glockmann A, Ziegler R, Willich SN, Kiene H: Anthroposophic medical therapy in chronic disease: a four-year prospective cohort study. BMC Complement Altern Med 2007, 7:10.

34. Fortin M, Lapointe L, Hudon C, Vanasse A: Multimorbidity is common to family practice: is it commonly researched? Can Fam Physician 2005, 51:244-245.

35. van den Akker M, Buntinx F, Metsemakers JF, Roos S, Knottnerus JA: Multimorbidity in general practice: prevalence, incidence, and determinants of co-occurring chronic and recurrent diseases. J Clin Epidemiol 1998, 51(5):367-375.

36. Laux G, Kuehlein T, Rosemann T, Szecsenyi J: Co- and multimorbidity patterns in primary care based on episodes of care: results from the German CONTENT project. BMC Health Serv Res 2008, 8:14.

37. Kaufman DW, Kelly JP, Rosenberg L, Anderson TE, Mitchell AA: Recent patterns of medication use in the ambulatory adult population of the United States: the Slone survey. JAMA 2002, 287(3):337-344.

38. Chan DC, Hao YT, Wu SC: Characteristics of outpatient prescriptions for frail Taiwanese elders with long-term care needs. Pharmacoepidemiol Drug Saf 2009, 18(4):327-334.

39. Gokce Kutsal Y, Barak A, Atalay A, Baydar T, Kucukoglu S, Tuncer T, Hizmetli S, Dursun N, Eyigor S, Saridogan M, et al: Polypharmacy in the elderly: a multicenter study. J Am Med Dir Assoc 2009, 10(7):486-490.

40. Friedel WE, Matthes H, Bock PR, Zanker KS: Systematic Evaluation of the Clinical Effects of Supportive Mistletoe Treatment within Chemo- and/or Radiotherapy Protocols and Long-Term Mistletoe Application in Nonmetastatic Colorectal Carcinoma: Multicenter, Controlled, Observational Cohort Study. J Soc Integr Oncol 2009, 7(4):137-145. 
41. Hamre HJ, Kiene $H$, Kienle GS: Clinical research in anthroposophic medicine. Altern Ther Health Med 2009, 15(6):52-55.

42. Hamre HJ, Witt CM, Glockmann A, Wegscheider K, Ziegler R, Willich SN, Kiene $\mathrm{H}$ : Anthroposophic vs. conventional therapy for chronic low back pain: a prospective comparative study. Eur J Med Res 2007, 12(7):302-310.

43. Jeschke E, Ostermann T, Vollmar HC, Kroz M, Bockelbrink A, Witt CM, Willich SN, Matthes $\mathrm{H}$ : Evaluation of prescribing patterns in a German network of CAM physicians for the treatment of patients with hypertension: a prospective observational study. BMC Fam Pract 2009, 10(1):78.

44. Cherniack EP, Ceron-Fuentes J, Florez H, Sandals L, Rodriguez O, Palacios JC: Influence of race and ethnicity on alternative medicine as a selftreatment preference for common medical conditions in a population of multi-ethnic urban elderly. Complement Ther Clin Pract 2008, 14(2):116-123.

45. Loera JA, Reyes-Ortiz C, Kuo YF: Predictors of complementary and alternative medicine use among older Mexican Americans. Complement Ther Clin Pract 2007, 13(4):224-231.

46. Tanaka MJ, Gryzlak BM, Zimmerman MB, Nisly NL, Wallace RB: Patterns of natural herb use by Asian and Pacific Islanders. Ethn Health 2008, 13(2):93-108.

47. Anlauf M: Antihypertonika. Arzneiverordnungs-Report 2006. Aktuelle Daten, Kosten, Trends und Kommentare. Springer VerlagSchwabe U, Paffrath D 2006, 408-424.

48. Tulner LR, Kuper IM, van Campen JP, Koks CH, Mac Gillavry MR, Beijnen JH, Brandjes DP: Treatment of hypertension in an elderly outpatient population in the Netherlands. Am J Geriatr Pharmacother 2009, 7(4):204-209.

49. Beckett NS, Peters R, Fletcher AE, Staessen JA, Liu L, Dumitrascu D, Stoyanovsky V, Antikainen RL, Nikitin Y, Anderson C, et al: Treatment of hypertension in patients 80 years of age or older. N Engl J Med 2008, 358(18):1887-1898

50. Gu Q, Burt VL, Paulose-Ram R, Dillon CF: Gender differences in hypertension treatment, drug utilization patterns, and blood pressure control among US adults with hypertension: data from the National Health and Nutrition Examination Survey 1999-2004. Am J Hypertens 2008, 21(7):789-798.

51. Gasse C, Hense HW, Stieber J, Doring A, Liese AD, Heller G, Keil U: Factors associated with differences in antihypertensive drug treatment: results from the MONICA Augsburg Population Surveys 1989/90 and 1994/95. Soz Praventivmed 2002, 47(2):128-142.

52. Birks J, Grimley Evans J: Ginkgo biloba for cognitive impairment and dementia. Cochrane Database Syst Rev 2007, , 2: CD003120.

53. Baurle $\mathrm{P}$, Suter A, Wormstall H: Safety and effectiveness of a traditional ginkgo fresh plant extract - results from a clinical trial. Forsch Komplementmed 2009, 16(3):156-161.

54. Ginkgohaltige Präparate bei Alzheimer Demenz. [http://www.iqwig.de/ download/A05-

19B_Abschlussbericht_Ginkgohaltige_Praeparate_bei_Alzheimer_Demenz. pdf].

55. van den Bussche $H$, Kaduszkiewicz $H$ : [Prescription patterns and effectiveness perception of anti-dementia drugs - A comparison between General Practitioners, Neurologists and Psychiatrists]. Nervenheilkunde 2005, , 24: 485-492.

56. Hach I, Rentsch A, Krappweis J, Kirch W: [Psychopharmaceutical prescriptions to older people. A comparison between patients in agedand nursing homes, outpatient treatment with nursing care and outpatients without nursing care]. Z Gerontol Geriatr 2004, 37(3):214-220.

57. Trifiro G, Savica R, Morgante L, Vanacore N, Tari M, Moretti S, Galdo M, Spina E, Caputi AP, Arcoraci V: Prescribing pattern of anti-Parkinson drugs in Southern Italy: cross-sectional analysis in the years 2003-2005. Parkinsonism Relat Disord 2008, 14(5):420-425.

58. Trifiro G, Sini G, Sturkenboom MC, Vanacore N, Mazzaglia G, Caputi AP, Cricelli C, Brignoli O, Aguglia E, Biggio G, Samani F: Prescribing pattern of antipsychotic drugs in the Italian general population 2000-2005: a focus on elderly with dementia. Int Clin Psychopharmacol 2010, 25(1):22-8.

59. Coca V, Nink K, Schröder H: Arneiverordnungen nach Alter und Geschlecht. Arzneiverordnungs-Report 2007 Aktuelle Daten, Kosten, Trends und Kommentare Springer VerlagSchwabe U, Paffrath D 2007, 919-1044.

60. Himmel W, Hummers-Pradier E, Kochen MM: [Health services research in general practice. A new approach]. Bundesgesundheitsblatt Gesundheitsforschung Gesundheitsschutz 2006, 49(2):151-159.

\section{Pre-publication history}

The pre-publication history for this paper can be accessed here: http://www.biomedcentral.com/1471-2318/10/48/prepub

doi:10.1186/1471-2318-10-48

Cite this article as: Jeschke et al:: Pharmacotherapy of elderly patients in everyday anthroposophic medical practice: a prospective, multicenter observational study. BMC Geriatrics 2010 10:48.

\section{Submit your next manuscript to BioMed Central and take full advantage of:}

- Convenient online submission

- Thorough peer review

- No space constraints or color figure charges

- Immediate publication on acceptance

- Inclusion in PubMed, CAS, Scopus and Google Scholar

- Research which is freely available for redistribution 